\title{
PISA's Reading Assessment and Its Implication
}

\author{
Yanjuan Huo \\ School of Foreign Languages, Shanghai Institute of Technology, Shanghai, China \\ Email: huoyanjuan@sit.edu.cn
}

How to cite this paper: Huo, Y. J. (2019) PISA's Reading Assessment and Its Implication. Creative Education, 10, 2504-2508. https://doi.org/10.4236/ce.2019.1011178

Received: November 4, 2019

Accepted: November 24, 2019

Published: November 27, 2019

Copyright $\odot 2019$ by author(s) and Scientific Research Publishing Inc. This work is licensed under the Creative Commons Attribution International License (CC BY 4.0).

http://creativecommons.org/licenses/by/4.0/

\begin{abstract}
The present research tries to analyze the assessment of reading competence issued by the Programme for International Student Assessment (PISA). From the brief introduction of PISA including the background, aims, expectations, and aspects, the current research is intended to gain insight from the objective and assessment of education, the suggestions for policymakers and the reading skills students need to acquire.
\end{abstract}

\section{Keywords}

PISA, Assessment, Language Policy

\section{Brief Introduction of PISA}

In response to the need for cross-nationally comparable evidence on performance of students, the Organization for Economic Co-Operation and Development (OECD) launched a triennial international survey that evaluates education systems worldwide by testing the skills and knowledge of 15 -year-old students acquiring key knowledge and skills that are essential for full participation in modern societies around the world known as the Programme for International Student Assessment (PISA). The PISA assessment, which is a three-yearly global assessment, examines students' ability in using cognitive skills in key subject areas of Reading Literacy, Mathematics Literacy and Science Literacy. Those students are mainly in grades 7-12 near the end of their compulsory education. The PISA assessment, a commitment by governments to monitor the outcomes of education systems, takes a broad approach to measuring knowledge, skills and attitudes that reflect current changes in school priorities. The OECD compares the academic performance of 15-year olds through its PISA, describing the assessment as the world's premier yardstick for evaluating the quality, equity and efficiency of school systems. The PISA assessment examines how well students can extrapolate from what they have learned and can apply that knowledge in 
unfamiliar settings moving beyond the school-based approach towards the use of knowledge in tasks and challenges. The PISA assessment is based on a dynamic model of lifelong learning in which new knowledge and skills necessary for successful adaptation to a changing world are continuously acquired throughout life. The content of PISA covers the domains of reading, mathematics and science. From PISA test, students are not only to be tested reproducing specific subject matter knowledge, but also extrapolating from what they have learned and applying their knowledge in various situations within each domain. For the assessment cycle of PISA, it takes place every three years with a strategic plan in place extending through to 2015 and each of these cycles looks in depth at a major domain (OECD, 2008).

\section{The Reading Ability Assessed by PISA}

In reading examination of PISA, students are expected to demonstrate their proficiency in locating information, including both accessing and retrieving information within a piece of text, and searching for and selecting relevant text; understanding text, including both acquiring a representation of the literal meaning of text and constructing an integrated representation of text; and evaluating and reflecting on text, including both assessing its quality and credibility, and reflecting on content and form. The reading ability of PISA plans to assess can be shown in the following framework in Figure 1 (OECD, 2008).

From this figure, it is clear that five aspects including retrieving information, forming a broad understanding, developing an interpretation, reflecting on and evaluating the content of a text, reflecting on and evaluating the form of a text as five separate subscale, for reporting on reading literacy. Figure 1 shows the relationship between the five aspects targeted in the test development and the three broad aspect categories: access and retrieve, integrate and interpret, reflect and evaluate. This figure is very clear guidance for teachers and students, which

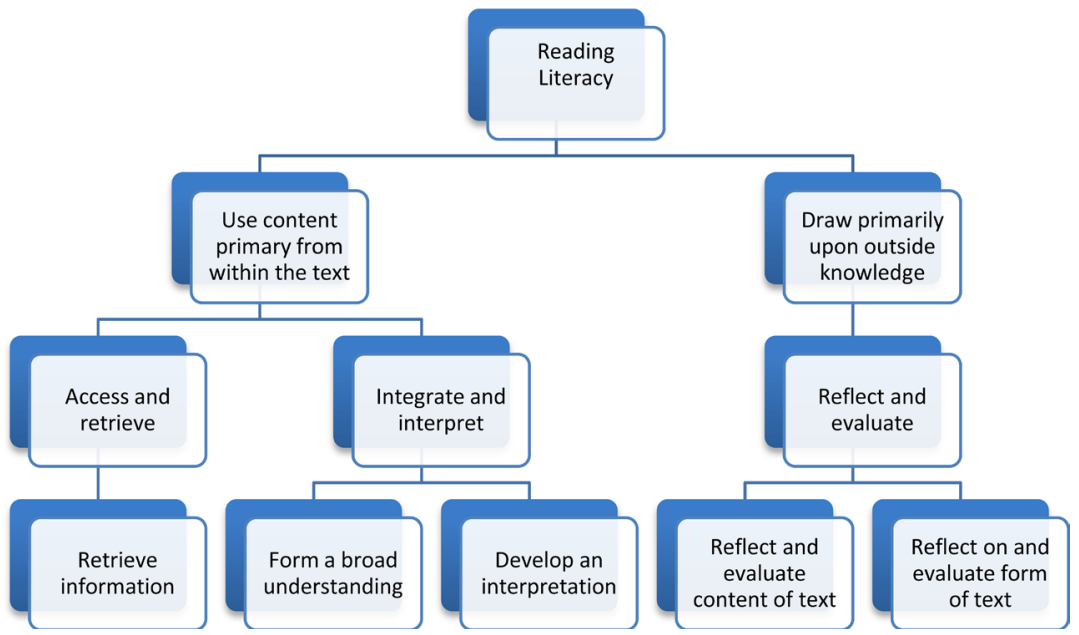

Revised from the source: OECD (2008) PISA 2009 assessment framework: Key competencies in reading, mathematics and science. Paris: OECD (Figure 1.3, p. 35).

Figure 1. Relationship between the reading framework and the aspect subscales. 
shows the reading processes that students need to be performed and the settings in which knowledge and skills are applied. In the real teaching, the teachers should intentionally guide the five aspects of reading abilities as the target of reading curriculum. If students learn by themselves they also can follow this graph to train their reading proficiency.

China actively participates in the international test. Up until 2015, young people from Shanghai took the PISA exam and since 2018, the national Ministry of China has carried out piloting of PISA in several provinces such as Jiangsu and Guangdong and the municipalities of Beijing and Shanghai, whose students participated in the two-hour test as preparation for fuller participation of China which the further step towards full participation of the whole of China in PISA. Basic statistics relating to Chinese municipalities and provinces participating in PISA can be found below (OECD, 2016) (Figure 2).

This is a welcome sign of increased co-operation between the OECD and China. Students from Shanghai score top-ranked in the world in some of the PISA exams, but there are still some questions difficult for our students to finish. Take PISA 2009 as an example, mobile phone safety question 11 (OECD, 2010):

"It is difficult to prove that one thing has definitely caused another". What is the relationship of this piece of information to the Point 4 Yes and No statements in the table are mobile phones dangerous?

A. It supports the Yes argument but does not prove it.

B. It proves the Yes argument.

C. It supports the No argument but does not prove it.

D. It shows that the No argument is wrong.

Proportion of students providing correct response to mobile phone safety question 11 can be shown in Figure 3 (Thomson, Hillman, \& De Bortoli, 2013).

Among the reading assessment questions, mobile phone safety questions require students to reflect and evaluate a text, which is the most difficult task in the mobile phone safety unit. Shanghai-China's performance on this item was relatively weak. The data from PISA can make us reflect our strength and weakness of our education.

\section{Implication}

The Insight gained from the study of PISA assessment of reading competence,

\begin{tabular}{lrrrr}
\hline \multicolumn{1}{c}{ Municipality/Province } & $\begin{array}{l}\text { Population } \\
\text { (in million) }\end{array}$ & $\begin{array}{c}\text { Area } \\
\text { (in km } \mathbf{~}^{2}\end{array}$ & $\begin{array}{c}\text { GDP } \\
\text { (in CNY } \text { trillion) }\end{array}$ & $\begin{array}{c}\text { GDP per capita } \\
\text { (in CNY) }\end{array}$ \\
\hline Beijing municipality & 21516 & 16410 & 2.133 & 99136 \\
Shanghai municipality & 24257 & 6340 & 2.356 & 97127 \\
Jiangsu province & 79600 & 102600 & 6.509 & 81771 \\
Guangdong province & 107240 & 179800 & 6.779 & 63213 \\
\hline
\end{tabular}

Source: OECD (2016) Education in CHINA a snapshot (Figure 1, p. 8).

Figure 2. Basic statistics relating to Chinese municipalities and provinces participating in PISA. 


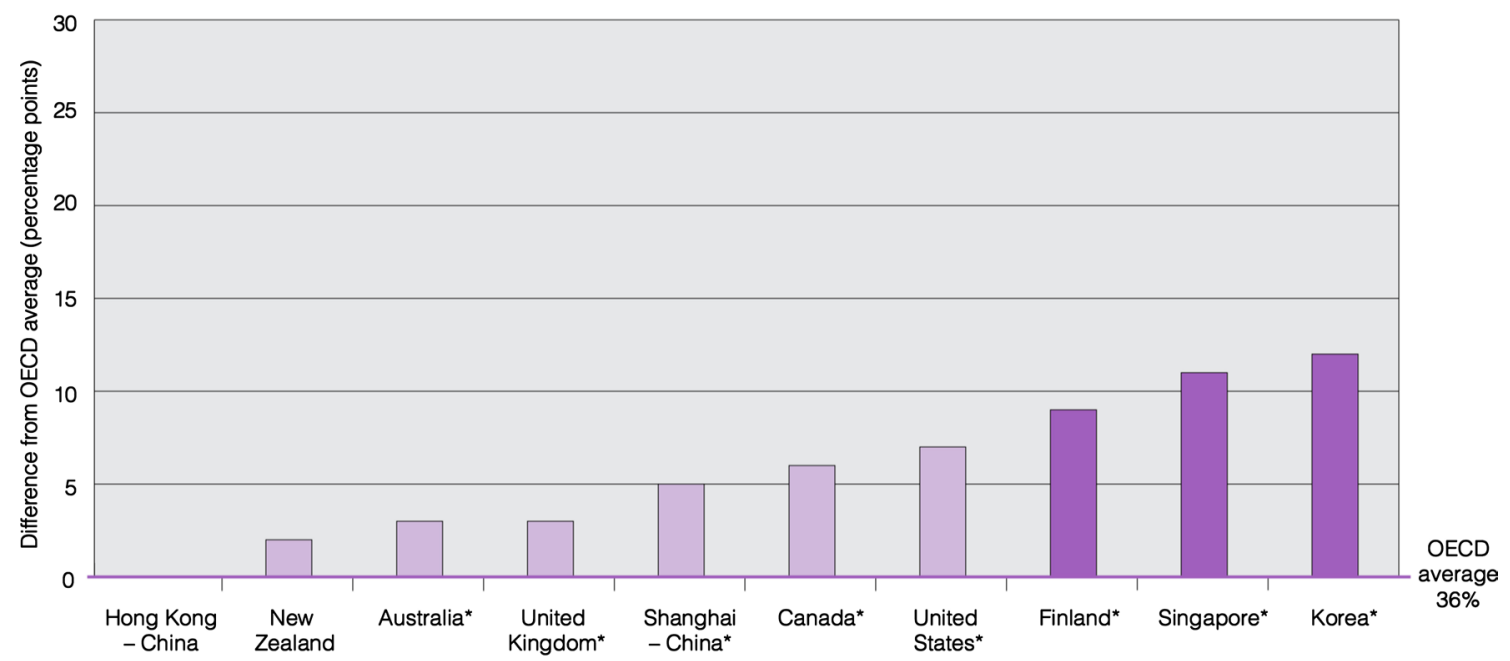

Source: A teacher's guide to PISA reading literacy (2013) (Figure 3.7, p. 38).

Figure 3. Proportion of students providing correct response to mobile phone safety question 11.

would undoubtedly contribute to a better formulation of the objective of education, the assessment of education and would definitely improve efficiency and effectiveness of our teaching of reading. The term "reading literacy" as used in PISA includes a wide range of cognitive competencies, which can give insights of the objective of education, from basic knowledge of words, grammar and larger linguistic and textual structures and features, to knowledge about the world. The purpose of education is preparing students ready to face the challenges of future life and to deal with the problems and communication in the workplaces. The foundational nature of reading literacy skills as key to all areas of education and beyond which can not only facilitate students' lifelong learning ability but also contribute to the benefit of individuals' social integration and personal development. For the assessment of education, the national and regional assessment should promote formative assessment, as a means to meeting the goals of lifelong learning. The assessment may help create greater equity of student outcomes. The unique feature of PISA assessment is that PISA not only examines students can reproduce knowledge but also can tell how well students can apply knowledge they have learned in the unfamiliar settings to solve the problem. The quantitative and qualitative evidence are both very important to the real teaching planning. It is vital to the widespread adoption of $21^{\text {st }}$ century skills in our schools, so that we must move from primarily measuring discrete knowledge to measuring students' ability to think critically, examine problems, gather information, and make informed, reason decisions while using technology. The current summative assessment is better to incorporate formative assessment in order to raise levels of student achievement, and better enable teachers to meet the needs of increasingly diverse student populations, helping to close gaps in equity of student outcomes. For policy makers, PISA is an ongoing programme that offers insights for education policy and practice which was designed to assist governments in monitoring the outcomes of education systems in terms of student 
achievement on a regular basis and within an internationally accepted common framework by comparing students performing on a set of common tasks. The findings allow policy makers around the world to gauge the knowledge and skills of students in their own countries and to set policy targets against measurable goals achieved by other education systems, and learn from policies and practices applied elsewhere in comparison with those in other countries, that is why more and more policy makers are using the results of studies such as PISA to make decisions about education. PISA collects information about students' background, their approaches to learning and their learning environments. As PISA shows us, it is critical to make sure the broad coverage of what students read and for what purposes they read, both in and outside of school. Scholars, teachers and students should be sent abroad to visit, study and engage in advanced studies to strengthen the cooperation and improve the teaching and learning. They should also be given more opportunities to exchange teaching ideas, share joint research projects and enhance international student dialogues.

\section{Conclusion}

In order to make sure that students are prepared to meet the challenges of future life, it is necessary and feasible to develop reading abilities of students in language teaching and learning.

\section{Acknowledgements}

I would like to thank for Shanghai Institute of Technology's unfailing support. This paper has been generously supported by: 391100190016037-A21 2019 Arts Project provided by Shanghai Institutes of Technology; 39120K196035-A06 2019 Newly introduced talent project provided by Shanghai Institutes of Technology; 33110L192012-A17 The Party construction at the primary level in universities provided by Shanghai Institutes of Technology.

\section{Conflicts of Interest}

The author declares no conflicts of interest regarding the publication of this paper.

\section{References}

OECD (2008). PISA 2009 Assessment Framework: Key Competencies in Reading, Mathematics and Science. Paris.

OECD (2010). PISA 2009 Results: What Students Know and Can Do-Student Performance in Reading, Mathematics and Science (Volume I). http://dx.doi.org/10.1787/9789264091450-en

OECD (2016). Education in CHINA a Snapshot. https://www.oecd.org/china/Education-in-China-a-snapshot.pdf

Thomson, S., Hillman, K., \& De Bortoli, L. (2013). A Teacher's Guide to PISA Reading Literacy. https://www.acer.org/files/PISA_Thematic_Report_-_Reading_-_web.pdf 